\title{
EXPERIMENTAL MEasurement OF CUTTING FORCES IN THE TURNING TECHNOLOGY
}

\author{
DUBOVSKA, R.; MAJERIK, J. \& BASKA, I.
}

Abstract: The main aim of this scientific study is to assess the contribution of surface layers of alloy $\mathrm{AlCu} 3 \mathrm{MgMnPb}$ by determining the experimental measurement of cutting forces in the turning technology with the coated carbide cutting insert. This experimental study is a continuation of the solutions of grant VEGA no. 1/9428/02 titled "The technological heredity of the machined surfaces - surface integrity". The first chapter of this paper discussed about the possibilities and technological challenges in turning of Al-alloys. The second chapter discusses about technological characteristics of cutting process and cutting forces. In the third and fourth chapter is described the measurement of cutting forces in turning by Kistler dynamometer. This paper, together with published results is a basis that will enable optimizing the quality of turning process, automotive parts of their dominant functional areas.

key words: cutting forces, Measurement, dynamometer KISTLER, machining process, machined surfaces
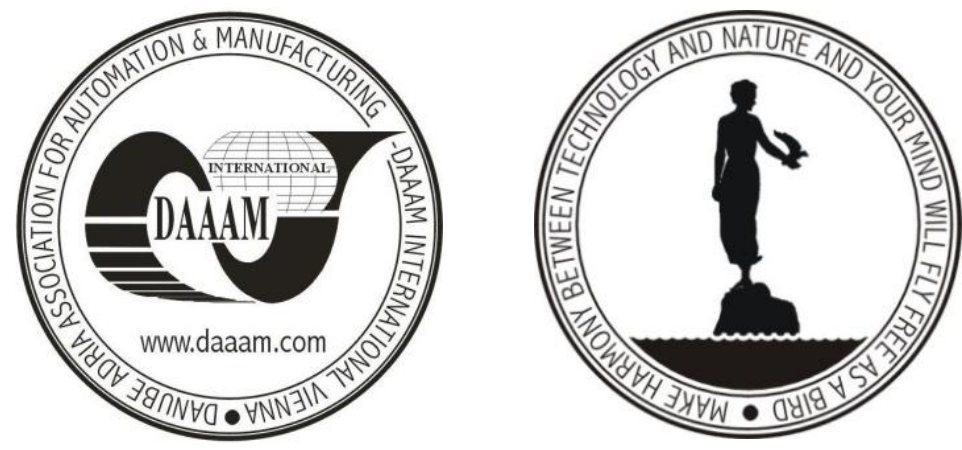

Authors' data: Univ.Prof. Dipl.-Ing. Dr. Sc. Dubovska, R[ozmarina]; Dipl.-Ing. PhD. Majerik, J[ozef]; Dipl.-Ing. PhD. Baska, I[van], University of Hradec Kralove, Namesti Svobody 301, 500 03, Hradec Kralove, Czech republic, rozmarina.dubovska@uhk.cz, jozefmajerik@yahoo.com, ivanbaska83@gmail.com

This Publication has to be referred as: Dubovska, R[ozmarina]; Majerik, J[ozef] \& Baska, I[van] (2012). Experimental Measurement of Cutting Forces in the Turning Technology, Chapter 22 in DAAAM International Scientific Book 2012, pp. 255266, B. Katalinic (Ed.), Published by DAAAM International, ISBN 978-3-90150986-5, ISSN 1726-9687, Vienna, Austria

DOI: $10.2507 /$ daaam.scibook.2012.22 


\section{Introduction}

The main aim of this experimental paper is to study, analyze and realize the experimental measurement of cutting forces at turning of rotational parts made from aluminium alloy $\mathrm{AlCu} 3 \mathrm{MgMnPb}$. This measurement was successively analyzed and experimentally verified on selected sample materials (in experimental measuring of the cutting forces during the turning process of parts and measured and results designated with the piezoelectric KISTLER dynamometer). Experiment team of authors is limited to the measurement of cutting forces in turning aluminum alloy as the material used in the automotive industry. Is a partial solution of the project dealing with the production of dominant functional areas in a university research cooperation and networking of manufacturing practices to the requirements of the industry to improve the quality of the machining process, and operating characteristics of the final product.

Application materials for the cutting tools are defined by their physical, chemical, thermal and mechanical properties (Humar, 2008). The term does not include only a machining process or a description of how to make machinery component removal of excess material, but also clarifying and explaining existing factors and phenomena in the machining process. Machining is therefore also its scientific, not only practical part. The theory provides hypotheses that are experimentally verified and verification of hypothesis becomes a theory validation.

In theory aside the agreed convention for marking and cutting action of cutting forces, as well as forces that are associated with an internal resistance of the cutting material (Piska \& Forejt, 2006).

One of the management strategies for business success in the market is a strategy of continuous improvement of production quality through the implementation of quality management and continuous improvement. Improving product quality then affects not only the production processes, but also postproduction activities (Jambor, 2010).

One of the main process engineering company is a manufacturing process that can be improved, including through implementation of new technologies and production processes in turning to activities related to experimental measurements of cutting forces in turning technology.

Cutting force is tied to the relative movement between tool and workpiece. As relates to the resistance to motion, it cannot be regarded as a constant variable in time (Beno, 1999).

Research on cutting forces in machining of metals is not only practical but also theoretical importance. Theoretical knowledge of the cutting forces to refine theories about the cutting process. In practice, again knowledge of the importance of cutting forces for design tools, the selection of cutting conditions, calculations and design of machine tools etc. (Neslusan, 2009).

Links between technology and machining surface quality, building on their functionality in the future must cover the entire technological world, they show ways to deal with ever-increasing demands on product quality and offered use of reserves resulting (Batora \& Vasilko, 2000). 


\section{Technological characteristics of machining process}

The cutting process is characterized by a number of technological parameters. The basic characteristics should be calculated geometric and strength values, work and cutting power, heat and temperature of cutting and vibration (shaking), machining system (Majerik \& Sandora, 2012).

Geometrical variables, which generally characterize the cutting process are: kinematic variables, feed, cutting edge, shot, cross section (chips) and machining performance (Kocman, 2004).

The kinematic parameters characterize the cutting process: the main cutting motion, cutting speed, feed movement and its direction, feed rate, cutting movement and its direction, the cutting speed of movement (Sandora et. al, 2006).

The longitudinal turning cylindrical surface is generally valid (1), (2), (3).

Cutting speed - $\quad v_{c}=\frac{\pi \cdot D \cdot n}{1000}\left(\mathrm{~m} \cdot \mathrm{min}^{-1}\right)$

Feed rate -

$$
v_{f}=\frac{f \cdot n}{1000} \quad\left(\mathrm{~m} \cdot \mathrm{min}^{-1}\right)
$$

Speed of cutting process - $\quad v_{e}=\sqrt{v_{c}^{2}+v_{f}^{2}} \quad\left(\mathrm{~m} \cdot \mathrm{min}^{-1}\right)$

\section{Cutting forces in turning technology}

The total cutting force induced by the action of the cutting tool to the workpiece is called the symbol F. For the analysis of power formula of the cutting process, the resulting cutting force $\mathrm{F}$ breaks down into relevant components. During the act of turning the workpiece cutting force $\mathrm{F}$, which is the vector can be separated into individual components (Vasilko et. al, 2006).

The active force $\mathrm{F}$ is determined by the projection of the total cutting force $\mathrm{F}$ to the working side of the plane shift $\mathrm{P}_{\mathrm{fe}}$. Passive force $\mathrm{F}_{\mathrm{p}}$ is also a component of the total cutting force $\mathrm{F}$, perpendicular to the plane $\mathrm{P}_{\mathrm{fe}}$ work side and the direction of the resultant cutting motion. Workforce $\mathrm{F}_{\mathrm{e}}$ expressed the general orthogonal cutting forces in the direction of cutting motion and is defined in the working plane side $\mathrm{P}_{\mathrm{fe}}$. The cutting force $\mathrm{F}_{\mathrm{c}}$ is a component of the total cutting force $\mathrm{F}$ identified the direction orthogonal to the main motion, i.e. vector in the direction of cutting speed $\mathrm{v}_{\mathrm{c}}$. It is the main component of cutting force. To determine the cutting force $F_{c}$ must know the specific cutting force (resistance) $k_{c}$, which is defined as the ratio of cutting forces $F_{f}$ and nominal cross sectional area (chip) AD.

$$
k_{c}=\frac{F_{c}}{A_{D}}\left(\mathrm{~N} \cdot \mathrm{mm}^{-2}=\mathrm{MPa}\right)
$$


Component of the total cutting force $\mathrm{F}$, defined in operational terms relating to the direction of the adjusting movement $F_{t}$, is given by the projection of the total force $F$ in the direction of the adjusting movement.

\subsection{Calculation of components of cutting forces}

Cutting force components were recorded in the computer considering the scheme of experimental measurement (Steiningerova \& Majerik, 2010).The process component operates as the resultant force F, which is the sum of the elemental forces. It is decomposed into the three components (Dubovska et al., 2011)

For turning cylindrical surface components, see here the following empirical dependences (5), (6), (7).

$$
\begin{aligned}
& F_{c}=C_{F_{c}} \cdot a_{p}^{x_{F_{c}}} \cdot f^{y_{F_{c}}} \\
& F_{p}=C_{F_{p}} \cdot a_{p}^{x_{F_{p}}} \cdot f^{y_{F_{p}}} \\
& F_{f}=C_{F_{f}} \cdot a_{p}^{x_{F_{f}}} \cdot f^{y_{F_{f}}}
\end{aligned}
$$

The known size of the specific cutting force (resistance) $k_{c}$ is possible to calculate the cutting force $\mathrm{F}_{\mathrm{c}}$ of the formula (8).

$$
F_{c}=k_{c} \cdot A_{D}=k_{c} \cdot h_{D} \cdot b_{D}=k_{c} \cdot a_{p} \cdot f
$$

Specific cutting force (resistance) $\mathrm{k}_{\mathrm{c}}$ varies considerably depending on workpiece, but also especially with section thickness $h_{D}$ (Beno \& Mankova, 2004). According to Beno \& Mankova, the mean values of $\mathrm{k}_{\mathrm{c}}$ for the various materials can see in Table 1 .

\begin{tabular}{|l|c|c|}
\hline \multicolumn{1}{|c|}{ Workpiece material } & $\mathbf{R}_{\mathbf{m}}(\mathbf{M P a})$ & $\mathbf{k}_{\mathbf{c}}(\mathbf{M P a})$ \\
\hline Non-alloy steel & 450 & 2100 \\
\hline Non-alloy steel & 600 & 2160 \\
\hline Non alloy steel & 700 & 2450 \\
\hline Cr-Ni steel & 500 & 2500 \\
\hline Cr-Ni steel & 700 & 2800 \\
\hline Grey cast iron & $140 \div 160$ & 1380 \\
\hline Grey cast iron & $161 \div 180$ & 1480 \\
\hline Grey cast oron & $181 \div 200$ & 1580 \\
\hline Bronze & $200 \div 300$ & 1100 \\
\hline Bronze & $310 \div 500$ & 1400 \\
\hline Al alloys & $180 \div 250$ & 850 \\
\hline Al alloys & $251 \div 350$ & 1150 \\
\hline
\end{tabular}

Tab. 1. The specific cutting resistance values of machined metals (Kocman, 2004).

Table 1 shows that the value of $k_{c}$ for the machining of aluminium alloys are significantly lower than in machining of steels, and smaller cutting forces are counted in turning $\mathrm{Al}$ alloys. 

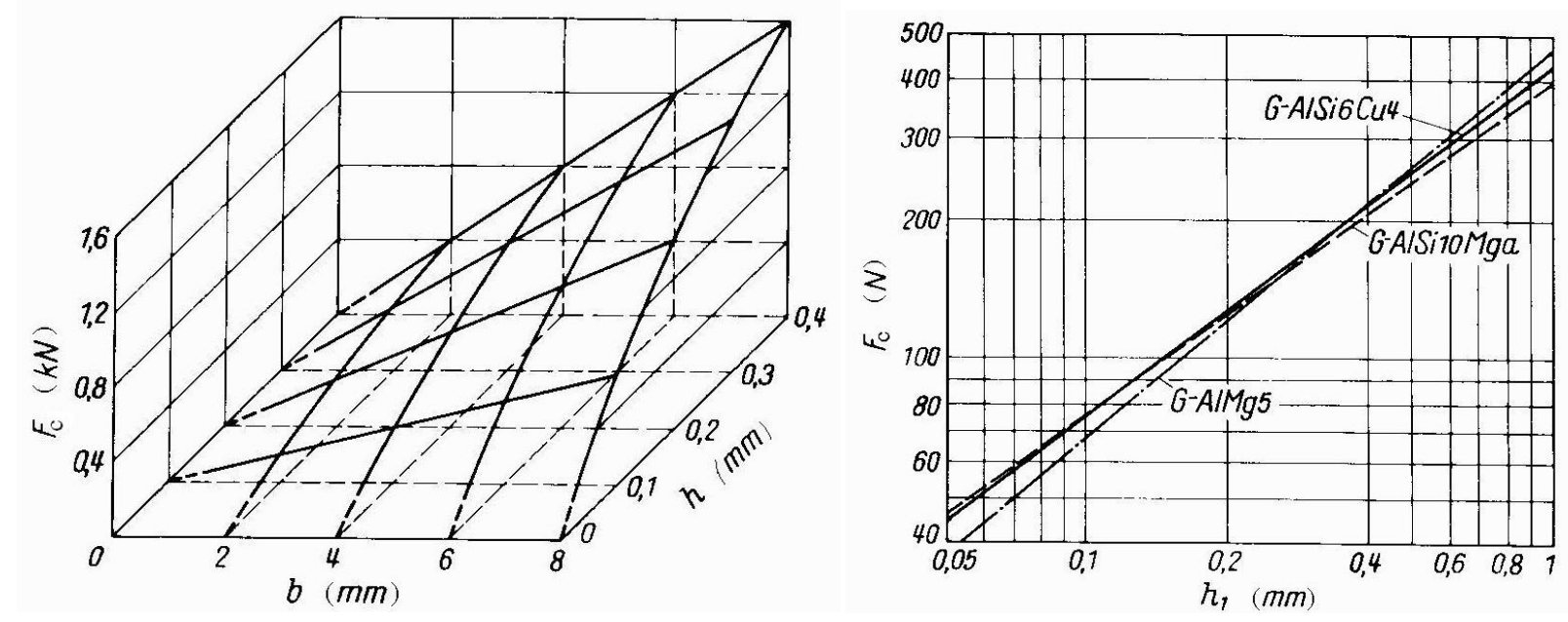

Fig. 1. Effect of width of cut $b$ and cut thickness of the cutting force $F_{c}$, the GK-Al alloy AlSi6Cu4, in turning the SK-K20 with geometry $\alpha=6^{\circ}, \gamma=15^{\circ}, \lambda=0^{\circ}$, and at $\mathrm{v}_{\mathrm{c}}=$ $750 \mathrm{~m} \cdot \mathrm{min}^{-1}$. Cutting force $\mathrm{F}_{\mathrm{c}}$, depending on the slice thickness $\mathrm{h}$, referred to in $\mathrm{Al}$ alloys, in turning the $\mathrm{v}_{\mathrm{c}}=300 \mathrm{~m} \cdot \mathrm{min}^{-1}$ and $\mathrm{b}=\mathrm{a}_{\mathrm{p}}=1,0 \mathrm{~mm}$ (Baska, 2011).

When deviations from these conditions, the machining cutting force $F_{c}$ is calculated from the next relation (Majerik \& Sandora, 2012).

$$
F_{c}=b \cdot h \cdot k_{c} \cdot K_{\gamma} \cdot K_{v_{c}} \cdot K_{m} \cdot K_{V B}(\mathrm{~N})
$$

where:

$K_{\gamma} \quad$ - correction factor for rake angle $K_{\gamma}=1-\frac{\gamma-\gamma_{K}}{66,7^{\circ}}$

$K_{v_{c}}$ - correction factor for cutting speed ( $\left.\mathrm{SK}=1, \mathrm{RO}=1,15\right)$,

$K_{m}$ - correction factor for cutting material $\left(\mathrm{K}_{\mathrm{sk}}=1, \mathrm{~K}_{\mathrm{rk}}=0,9 \div 0,95\right)$,

$K_{V B}$ - correction factor for wear (for a sharp wedge $\mathrm{K}_{\mathrm{VB}}=1$, for a worn wedge $\mathrm{K}_{\mathrm{VB}}=$ $1,3 \div 1,5)$.

The direct capture components of cutting forces are most frequently used with piezoelectric dynamometer. It is possible to measure one, two, or three components of cutting force or torque. The basis of each dynamometer is a flexible element that is deformed by cutting forces (Beno \& Mankova, 2004).

\section{Experimental measurement \& results}

Experimental measuring of cutting forces in turning parts made of alloy were realized in laboratories of the Faculty of Mechanical Engineering-University of Zilina. The used machine tool was lathe SUI-40 with variable frequency control of rotation, without coolant application. Because coolant elimination from cutting process brings decrease overall manufacturing costs (Majerik, et. al, 2010).

In addition to experimental measurements were made to the statistical 
Dubovska, R.; Majerik, J. \& Baska, I.: Experimental Measurement of Cutting Forc...

treatment of the cutting force $\mathrm{F}_{\mathrm{c}}$ depending on the depth of cut and feed rate, as well as the dependence $\mathrm{T}=\mathrm{f}\left(\mathrm{v}_{\mathrm{c}}\right)$, in turning $\mathrm{Al}$ alloys in the manufacturing and evaluate it using the least squares method (Neslusan et al, 2007).

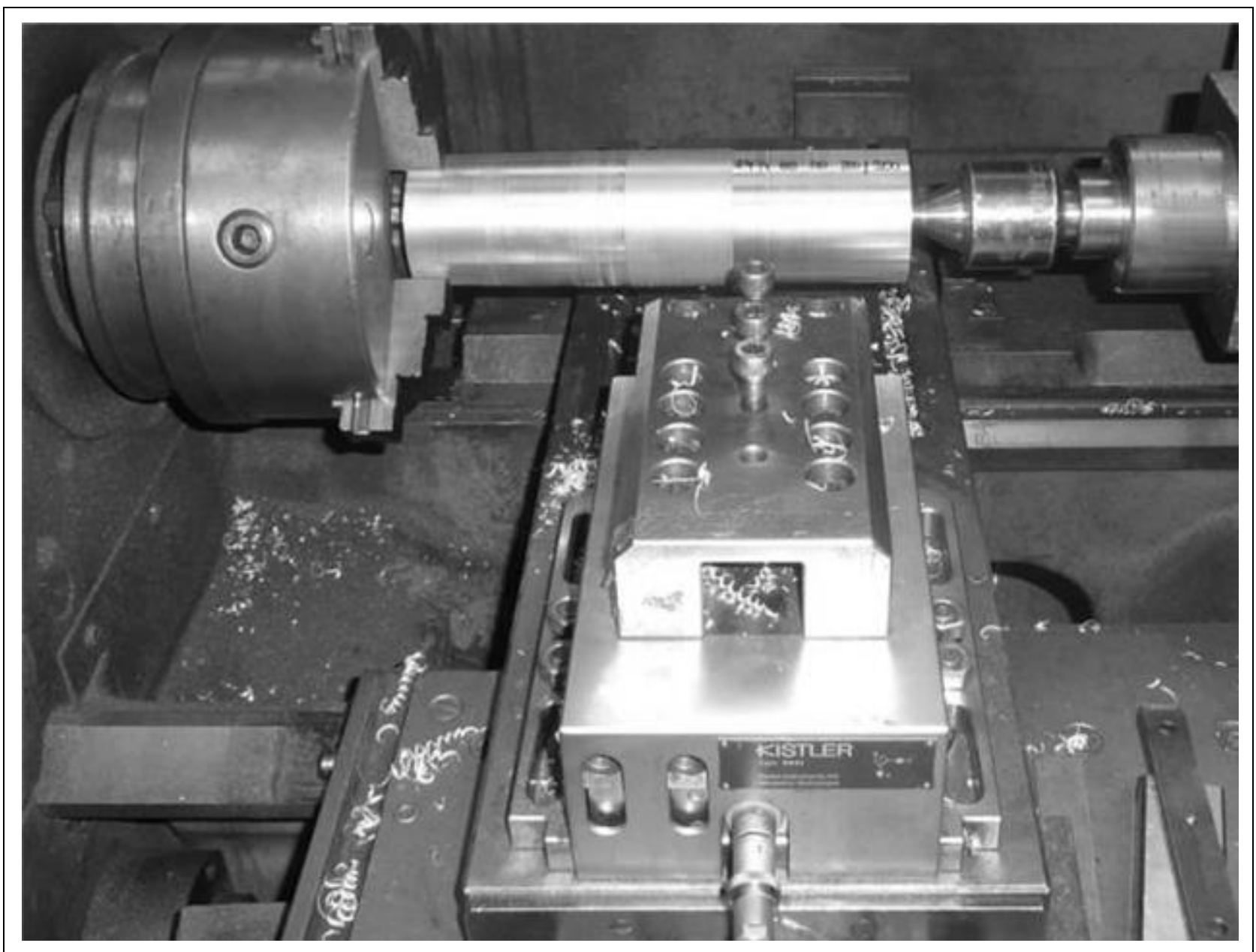

Fig. 2. Overall view of the piezoelectric KISTLER dynamometer during turning of workpiece material made of $\mathrm{AlCu} 3 \mathrm{MgMnPb}$ (Baska, 2011)

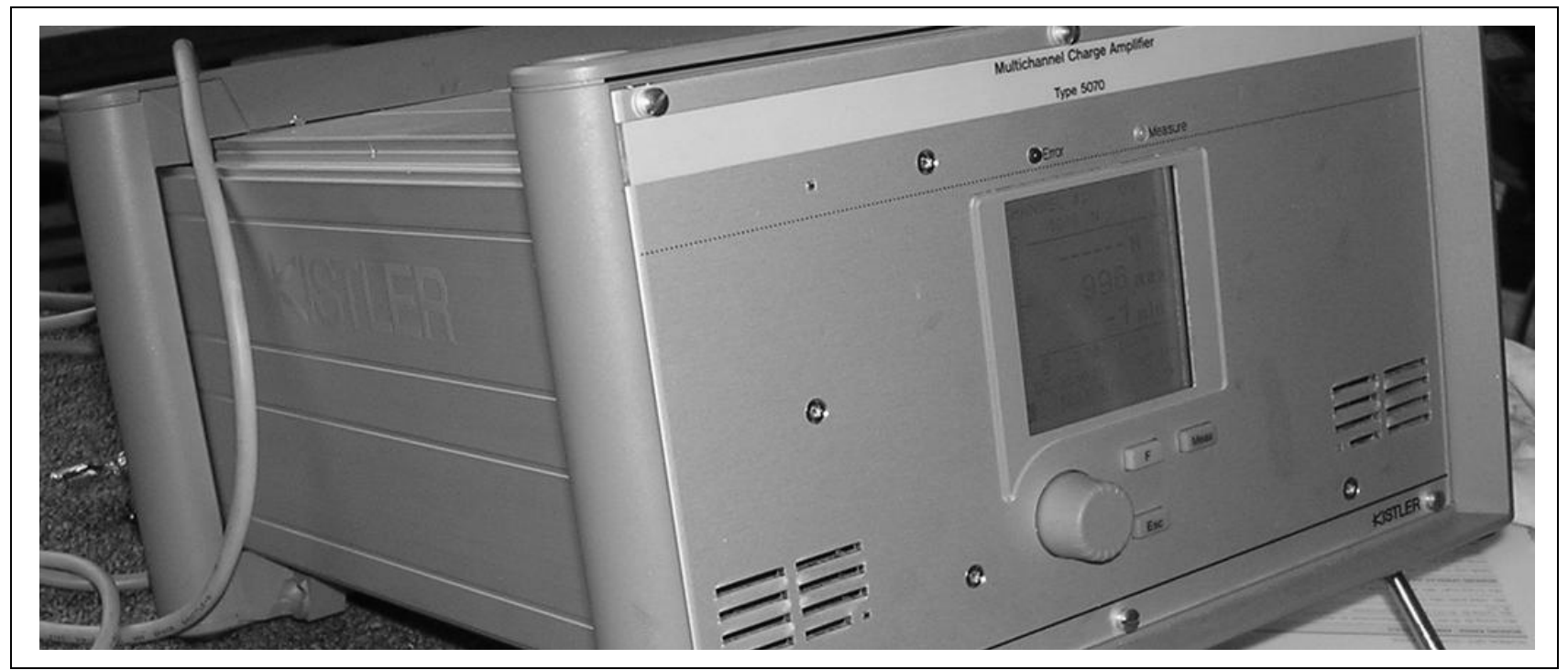

Fig. 3. Detail of KISTLER evaluation apparatus for measuring the cutting forces 
Proper writing methodology was created, which would be able to define the communication ways between single devices during running process (Danisova et al., 2011).

The frequency of rotation of the spindle lathe is: $\mathrm{n}=18451 \cdot \mathrm{min}^{-1}$, measured using a revolution counter. Variables of the cross section: $S=a_{p} . f\left(\mathrm{~mm}^{2}\right)$. Changing the cross-abstracted layer that is to say depth of cut, $a_{p}(\mathrm{~mm})$ at a constant feed rate $f_{o}=$ $0.1 \mathrm{~mm}$, respectively $\mathrm{f}$ the feed at a constant depth of cut $\mathrm{a}_{\mathrm{po}}=1,0 \mathrm{~mm}=$ const. The aim was to determine the constants $C_{F_{c}}^{\prime}$ and $C_{F_{c}}^{\prime \prime}$ exponents $x_{F_{c}}$ and $y_{F_{c}}$ from cutting forces:

$$
F_{c}=C_{F_{c}} \cdot a_{p}^{x_{F_{c}}} \cdot f^{y_{F_{c}}}
$$

The exponential equation after linearization using decimal logarithms entry is in the following logarithmical form:

$$
\log F_{c_{i}}=\log C_{F_{c}}+x_{F_{c}} \cdot \log a_{p_{i}}+y_{F_{c}} \cdot \log f_{i}
$$

where: $\quad \mathrm{i}=1,2, \ldots .6 \quad$ is number of measurements $\mathrm{N}$

The measured data are arranged in Table 2 and Table 3 , for $\mathrm{f}_{\mathrm{o}}=0.1 \mathrm{~mm}=$ const. and $\mathrm{a}_{\mathrm{po}}=1.0 \mathrm{~mm}=$ const. to determine the partial constants $C_{F_{c}}^{\prime}$ and $C_{F_{c}}^{\prime \prime}$ and exponents of single parametric dependence method of least squares:

$$
\begin{gathered}
F_{c}=C_{F_{c}^{\prime}}^{\prime} \cdot a_{p}^{x_{F_{c}}} \quad \ldots . . \text { for } \mathrm{f}_{\mathrm{o}}=0,101 \mathrm{~mm}=\text { const. } \\
F_{c}=C_{F_{c}}^{\prime \prime} \cdot f^{y_{F_{c}}} \quad \ldots . . \text { for } \mathrm{a}_{\mathrm{po}}=1,0 \mathrm{~mm}=\text { const. }
\end{gathered}
$$

\begin{tabular}{|l|l|l|l|l|l|l|}
\hline $\mathbf{a}_{\mathbf{p}}(\mathbf{m m})$ & $\mathbf{0 , 2 5}$ & $\mathbf{0 , 5}$ & $\mathbf{0 , 7 5}$ & $\mathbf{1 , 0}$ & $\mathbf{1 , 2 5}$ & $\mathbf{1 , 5}$ \\
\hline $\mathrm{F}_{\mathrm{c}}(\mathrm{N})$ & 22 & 45 & 67 & 90 & 107 & 127 \\
\hline $\mathrm{F}_{\mathrm{f}}(\mathrm{N})$ & 5 & 11 & 15 & 20 & 24,5 & 29 \\
\hline
\end{tabular}

Tab. 2. Measured values of $F_{c}$ and $F_{f}$ for insert CC: DCGT 11T304-K10 (H10)

Note: turning without coolant (dry turning), $\kappa_{\mathrm{r}}=93^{\circ}, \kappa_{\mathrm{r}}{ }^{\prime}=32^{\circ}, \varepsilon_{\mathrm{r}}=55^{\circ}, \mathrm{r}_{\varepsilon}=0,4 \mathrm{~mm}$, $\lambda \mathrm{s}=0^{\circ}, \mathrm{f}_{\mathrm{o}}=0,1 \mathrm{~mm}, \mathrm{v}_{\mathrm{c}}=400 \mathrm{~m} \cdot \mathrm{min}^{-1}$

\begin{tabular}{|l|l|l|l|l|l|l|}
\hline $\mathbf{f}(\mathbf{m m})$ & $\mathbf{0 , 0 2 3}$ & $\mathbf{0 , 0 5 4}$ & $\mathbf{0 , 1}$ & $\mathbf{0 , 1 5}$ & $\mathbf{0 , 2}$ & $\mathbf{0 , 3}$ \\
\hline $\mathrm{F}_{\mathrm{c}}(\mathrm{N})$ & 28 & 52 & 87 & 123 & 164 & 224 \\
\hline $\mathrm{F}_{\mathrm{f}}(\mathrm{N})$ & 14 & 15 & 20 & 23 & 24 & 26 \\
\hline
\end{tabular}

Tab. 3. Measured values of $F_{c}$ and $F_{f}$ for insert CC:DCGT 11T3040-K10 (H10)

$$
\text { Main cutting force: } \quad F_{c}=C_{F_{c}^{\prime}}^{\prime} \cdot a_{p}^{x_{F_{c}}}
$$


Dubovska, R.; Majerik, J. \& Baska, I.: Experimental Measurement of Cutting Forc...

Linearization using logarithms type decimal logarithm:

$$
\log F_{c_{i}}=\log C_{F_{c}}^{\prime}+x_{F_{c}} \cdot \log a_{p_{i}}
$$

Founded values of logarithms of the data are in Table 2 and in Table 4:

\begin{tabular}{|c|c|c|c|c|c|c|}
\hline & $\mathbf{F}_{\mathbf{c i}}[\mathbf{N}]$ & $\mathbf{a}_{\mathbf{p i}}[\mathbf{m m}]$ & $\log \mathbf{F}_{\mathbf{c i}}$ & $\log \mathbf{a}_{\mathbf{p i}}$ & $\log \mathbf{a}_{\mathbf{p i}}{ }^{2}$ & $\log \mathbf{a}_{\mathbf{p i}} \cdot \log \mathbf{F}_{\mathbf{c i}}$ \\
\hline 1 & 22 & 0,25 & 1,34242 & $-0,60206$ & 0,36246 & $-0,80822$ \\
\hline 2 & 45 & 0,5 & 1,65321 & $-0,30103$ & 0,09062 & $-0,49766$ \\
\hline 3 & 67 & 0,75 & 1,82607 & $-0,12494$ & 0,01561 & $-0,22815$ \\
\hline 4 & 90 & 1,0 & 1,95424 & 0 & 0 & 0 \\
\hline 5 & 107 & 1,25 & 2,02938 & 0,09691 & 0,00939 & 0,19666 \\
\hline 6 & 127 & 1,5 & 2,10380 & 0,17609 & 0,00310 & 0,37046 \\
\hline$\Sigma$ & & & 10,90900 & -0.75500 & 0,48677 & $-0,96691$ \\
\hline
\end{tabular}

Tab. 4. The logarithms of cutting force $\mathrm{Fc}$ and the $\mathrm{a}_{\mathrm{p}}$ to measure cutting forces.

Substituting the relations for the method of least squares:

$$
\begin{gathered}
x_{F_{c}}=\frac{N \cdot \sum \log a_{p_{i}} \cdot \log F_{c_{i}}-\sum \log a_{p_{i}} \cdot \sum \log F_{c_{i}}}{N \cdot \sum \log a_{p_{i}}^{2}-\left(\sum \log a_{p_{i}}\right)^{2}} \\
x_{F_{c}}=\frac{6 \cdot(-0,96691)-(-0,755) \cdot(10,909)}{6 \cdot(0,48677)-(-0,755)^{2}}=\frac{-5,80146+8,23630}{2,921-0,57}=\frac{2,43484}{2,351}=1,0357=\operatorname{tg} \alpha_{1} \\
\alpha_{1}=\operatorname{arctg} 1,0357=46^{\circ} \\
\log C_{F_{c}}^{\prime}=\frac{\sum \log F_{c_{i}}-x_{F_{c}} \cdot \sum \log a_{p_{i}}}{N}=\frac{11,691}{6}=1,94848
\end{gathered}
$$

Then: $\quad C_{F_{c}}^{\prime}=10^{1,94848}=88,8137$

We can write equations for the shape of the main cutting force $\mathbf{F}_{\mathbf{c}}=\mathbf{8 8 , 8 1 3 7} \cdot \mathbf{a}_{\mathbf{p}}{ }^{\mathbf{1 , 0 3 5 6}}$ The same procedure to determine the constant $C_{F_{c}}^{\prime \prime}$ and exponent $y_{F_{c}}$, for ratio $F_{c}=f(f)$

$$
\begin{aligned}
F_{c} & =C_{F_{c}}^{\prime \prime} \cdot f^{y_{F_{c}}} \\
\log F_{c_{i}} & =\log C_{F_{c}}^{\prime \prime}+y_{F_{c}} \cdot \log f_{i}
\end{aligned}
$$

Calculated values in Table 3 are shown in Table 5: 


\begin{tabular}{|c|c|c|c|c|c|c|}
\hline & $\mathbf{F}_{\mathbf{c i}}[\mathbf{N}]$ & $\mathbf{f}_{\mathbf{i}}[\mathbf{m m}]$ & $\log \mathbf{F}_{\mathbf{c i}}$ & $\log \mathbf{f}_{\mathbf{i}}$ & $\log \mathbf{f}_{\mathbf{i}}^{2}$ & $\log \mathbf{f}_{\mathbf{i}} \cdot \log \mathbf{F}_{\mathbf{c i}}$ \\
\hline 1 & 28 & 0,023 & 0,44716 & $-1,63827$ & 2,68393 & $-0,73257$ \\
\hline 2 & 52 & 0,054 & 0,71600 & $-1,26761$ & 1,60684 & $-0,90761$ \\
\hline 3 & 87 & 0,101 & 0,93952 & $-1,00432$ & 1,00866 & $-0,94358$ \\
\hline 4 & 123 & 0,162 & 1,08991 & $-0,79048$ & 0,62486 & $-0,86155$ \\
\hline 5 & 164 & 0,224 & 1,21484 & $-0,65758$ & 0,43241 & $-0,79885$ \\
\hline 6 & 224 & 0,282 & 1,35025 & $-0,54975$ & 0,30222 & $-0,74229$ \\
\hline$\Sigma$ & & & 5,7577 & $-5,90801$ & 6,65892 & $-4,9864$ \\
\hline
\end{tabular}

Tab. 5. The logarithms of cutting force $F_{c}$ and displacements of measured force.

$$
\begin{gathered}
y_{F_{c}}=\frac{N \cdot \sum \log f_{i} \cdot \log F_{c_{i}}-\sum \log f_{i} \cdot \sum \log F_{c_{i}}}{N \cdot \sum \log f_{i}^{2}-\left(\sum \log f_{i}\right)^{2}} \\
y_{F_{c}}=\frac{6 \cdot(-4,9864)-(-5,90801) \cdot(5,7577)}{6 \cdot 6,65892-(-5,90801)^{2}}=\frac{4,0981}{5,048}=0,812=\operatorname{tg} \alpha_{2} \\
\alpha_{2}=\operatorname{arctg} 0,812=39^{\circ} \\
\log C_{F_{c}}^{\prime \prime}=\frac{\left(\sum \log F_{c_{i}}-y_{F_{c}} \cdot \sum \log f_{i}\right)}{N}=\frac{10,556}{6}=1,759 \\
C_{F_{c}}^{\prime \prime}=10^{1,759}=57,411
\end{gathered}
$$

Then: $\quad \mathbf{F}_{\mathbf{c}}=\mathbf{5 7 , 4 1 1} \cdot \mathbf{f}^{\mathbf{0 , 8 1 2}}$

The calculated values are reported in double logarithmic coordinate system:

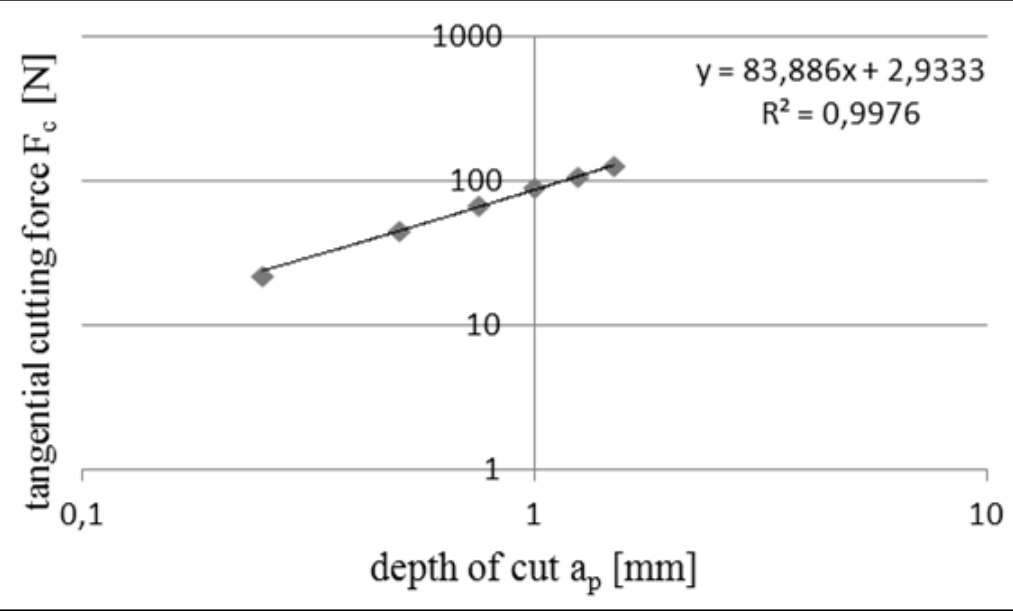

Fig. 4. Graphical dependence of $\mathrm{F}_{\mathrm{c}}=\mathrm{f}\left(\mathrm{a}_{\mathrm{p}}\right)$ in double logarithmic coordinate system (turned alloy $\mathrm{AlCu} 3 \mathrm{MgMnPb}$ ) at $\mathrm{v}_{\mathrm{c}}=400 \mathrm{~m} \cdot \mathrm{min}^{-1}, \mathrm{f}=0,1 \mathrm{~mm}$ 


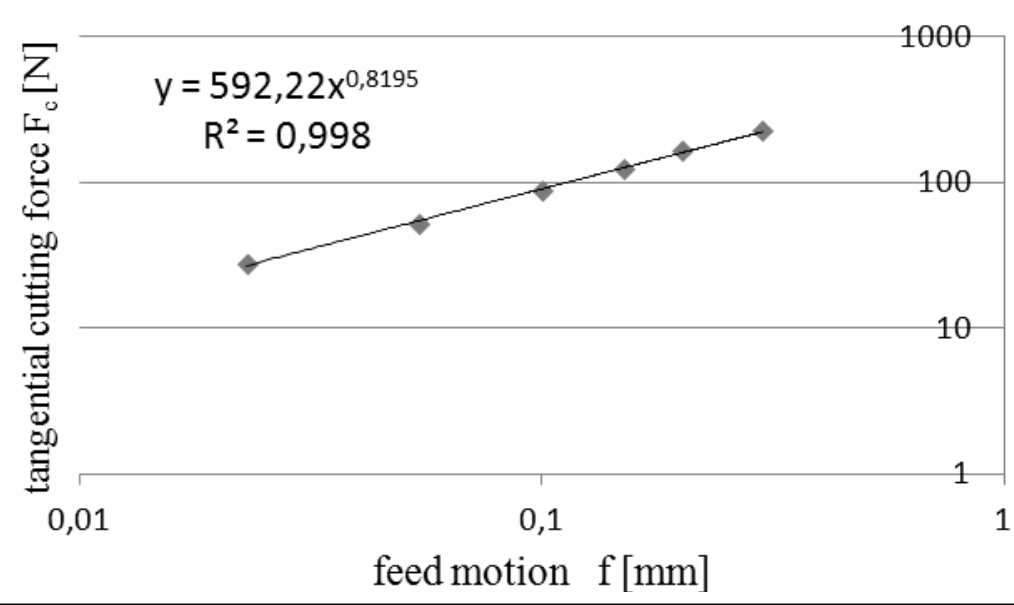

Fig. 5. Graphical dependence of $F_{c}=f(f)$ in double logarithmic coordinate system

Graphical dependence of the measured values of cutting forces depending on the depth of cut and feed rate are shown in Fig.6, and Fig.7, and their shape is as follows:

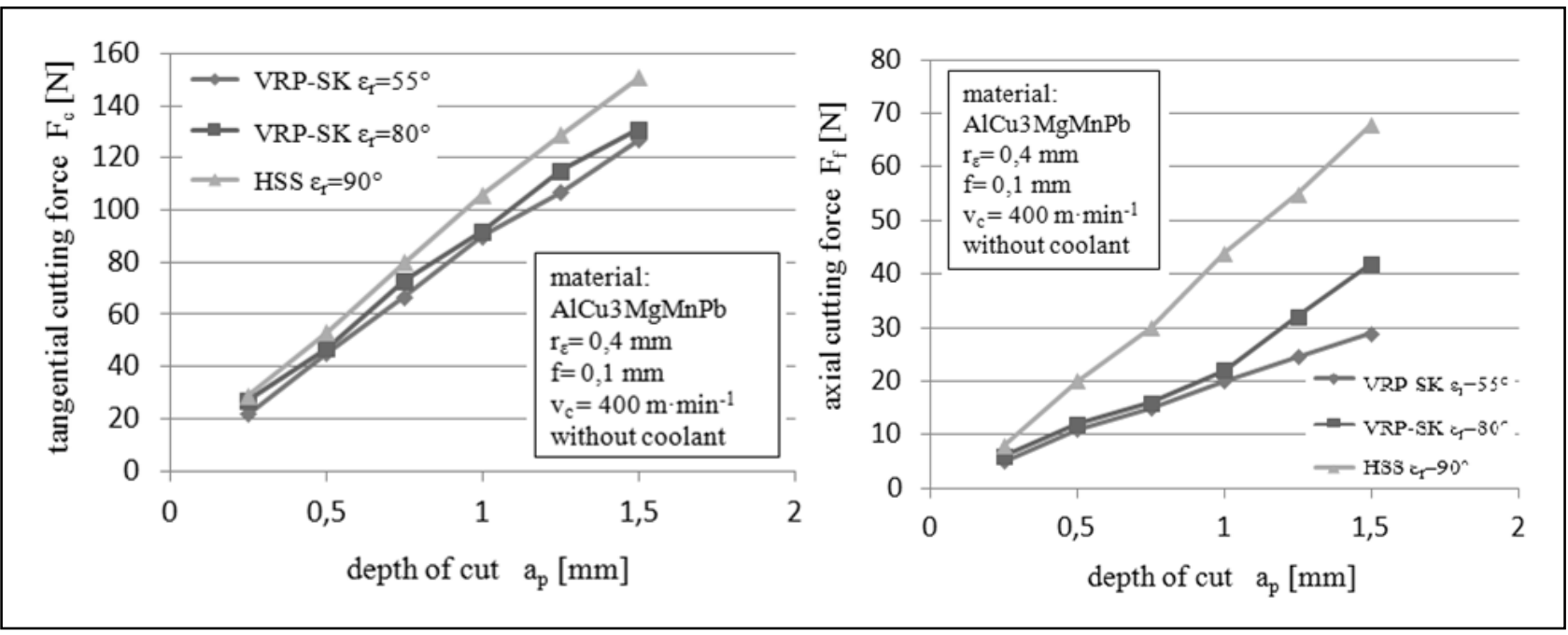

Fig. 6. Graphs based of cutting force $F_{c}$ and $F_{f}$ at a depth of cut for turning
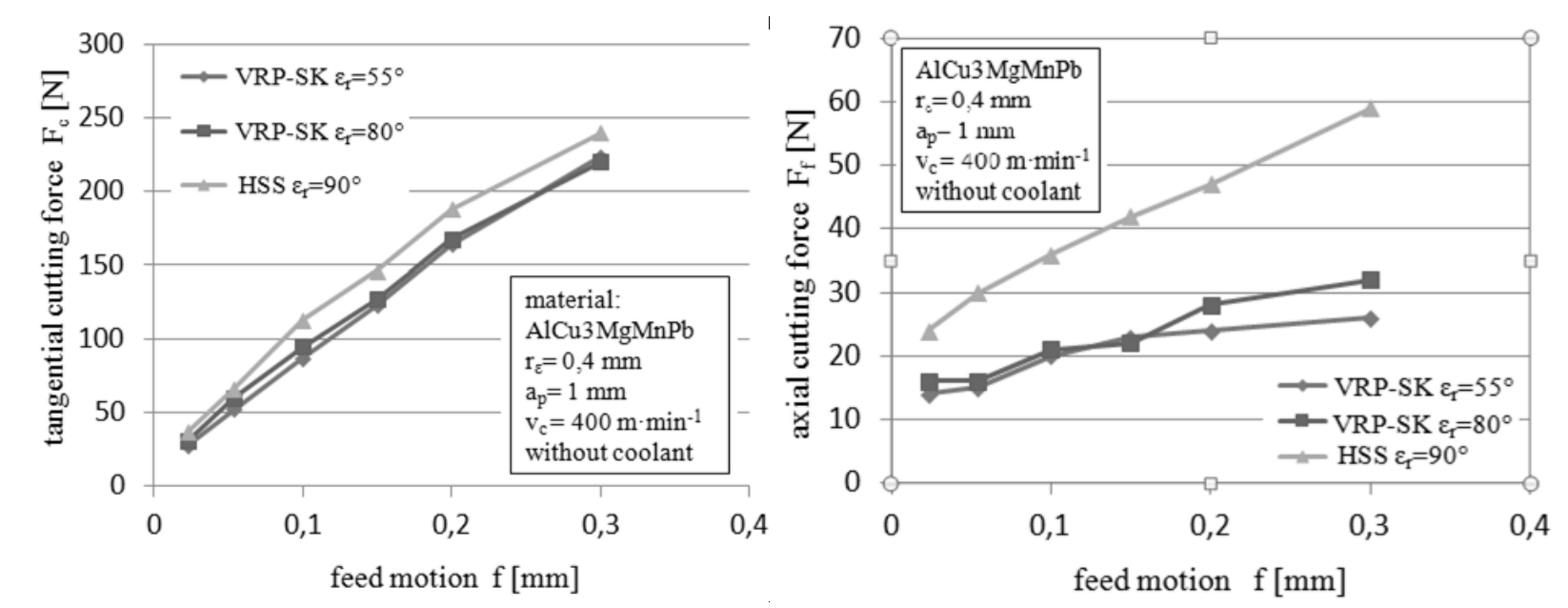

Fig. 7. Graphs based of cutting force $\mathrm{F}_{\mathrm{c}}$ and $\mathrm{F}_{\mathrm{f}}$ at a feed motion for turning 


\section{Conclusion}

Measurements of cutting forces in turning of aluminium alloy $\mathrm{AlCu} 3 \mathrm{MgMnPb}$ using a piezoelectric dynamometer KISTLER showed us a fact, that the cutting speed increases of $F_{c}$ resizing shift and a change in the depth of cut, dry with $v_{c}=400 \mathrm{~m}$. $\min ^{-1}, \mathrm{f}_{0}=0.1 \mathrm{~mm}, \mathrm{a}_{\mathrm{p} 0}=1 \mathrm{~mm}$. Graphic dependence of cutting force $\mathrm{F}_{\mathrm{c}}$ on the size of the feed and cutting depth are processed by the method of least squares in a logarithmic coordinate system. The theoretical benefit is also a fact that cutting forces $\mathrm{F}_{\mathrm{c}}$ are significantly smaller in turning $\mathrm{AlCu} 3 \mathrm{MgMnPb} \mathrm{Al}$ alloys, such as in turning steel with the same strength (only $30 \%$ of the value of steel component $\mathrm{F}_{\mathrm{f}}$ only $20 \%$ ) and grow well with the growth of feed and cutting depth. The practical benefit is the finding that in hardened aluminium alloy machinability is attained by $R_{a}$ good and improves with increasing the hardness (strength). Effect of cutting speed of change of force $F_{c}$ was not measured. That opens the new ways for further research in this area, to optimize the technological process of turning machine parts made from aluminium alloys in the production of their dominant functional areas.

On the basis of experience, we can state that the system of quality management processes is beneficial only if it is constantly improving. It is necessary to improve all activities and anything that can improve a company based on the constantly changing needs of the real experience and customer demand that is continuously gathering customer feedback and satisfaction regarding their views on the process improvement (Jambor, 2010).

Timely communication with customers and experience we can ensure a smooth launch of new standards, as the arrival of new technologies and systems with you and automatically gives them a positive change (Lechan \& Jambor, 2007).

The next step in the future study of the technological process of production of components for the automobile industry, the team of authors will study the integrity of the machined surface in terms of temperature fields of study and areas of technological system tool workpiece in the cutting process with the influence of cutting parameters on the temperature in the cutting zone.

\section{Acknowledgements}

The present scientific paper was to link the theory of machining of industrial practice. The practical part was conducted in collaboration Faculty of Mechanical Engineering University of Zilina, along with industrial firms of the region of Trencin. It also builds on the project VEGA 1/9428/02, which was successfully resolved at the Faculty of Special Technology in Trencin.

\section{References}

Batora, B.; Vasilko, K. (2000). Machined surfaces, technological heredity, functionality, FST TnUAD, ISBN 80-88914-19-1, Trencin, Slovakia

Beno, J. (1999). Theory of cutting metals, SjF TUKE, ISBN 80-7099-429-0, Kosice, Slovakia 
Dubovska, R.; Majerik, J. \& Baska, I.: Experimental Measurement of Cutting Forc...

Beno, J.; Mankova, I. (2004). Technological and material factors of machining, $\mathrm{SjF}$ TUKE, ISBN 80-7099-701-X, Kosice, Slovakia

Baska, I. (2011). Technological problems of machining parts made of aluminium alloys by turning, Dissertation work FST TnUAD, p.150, Trencin, Slovakia

Danisova, N.; Sebenova, S. \& Velisek, K. (2011). Application of seguence diagram within tool change during machining, Annals of DAAAM for 2011\&Proceedings of the 22nd International World Symposium, pp. 04590460, ISSN 1726-9679, ISBN 978-3-901509-70-4, Austria Center Vienna, 2326th November 2011, Katalinic, B. (Ed.), Vienna, Austria

Dubovska, R.; Majerik, J. \& Chochlikova, H. (2011). Physico-chemical state Stabilization of high strength steels machined surface, Proceedings in manufacturing systems, Vol.6, No.4, (2011) p. 75-80, ISSN 2067-9238

Humar, A. (2008). Materials for cutting tools, MM publishing, ISBN 978-80-2542250-2, Prague, Czech republic

Jambor, J. (2010). Analysis of the results of audits of quality management system sales service of cars, Quality Innovation Prosperity, Vol.14, No. 1-2, ISSN 1335-1745, p.1-8, Trencin, Slovakia

Lechan, P.; Jambor, J. (2007). SEAT Service quality management system, International scientific conference of Vehicles - New trends in construction and exploitation automobiles, Slovak University of Agriculture, ISBN 978-808069-942-0, Nitra 2007, Slovakia, p. 119-123

Kocman, K. (2004). Special technology - machining, UST FSI VUT, ISBN 80-2142562-8, Brno, Czech republic

Majerik, J.; Dubovska, R. \& Baska, I. (2010). Positive and negative theoretical and technological aspects of dry machining or with coolant application, University Review - Technology of special production, Vol.4, No.3, (2010) p. 25-29, ISSN 1337-6047

Majerik, J.; Sandora, J. (2012). The new progressive cutting tools and machining technology methods, FST TnUAD, ISBN 978-80-8075-515-7, EAN 9788080755 157, Trencin, Slovakia

Neslusan, M. (2009). Turning of hardened steels, SjF ZU, ISBN 978-80-554-104-1, Zilina, Slovakia

Neslusan, M.; Turek, S.; Brychta, J.; Cep, R.; Tabacek, M. (2007). Experimental methods in machining, SjF ZU, ISBN 978-80-8070-711-8, Zilina, Slovakia

Piska, M.; Forejt, M. (2006). Theory of machining, forming and cutting tools, UST FSI VUT, ISBN 80-214-2374-9, Brno, Czech republic

Sandora, J.; Martiskova, M.; Majerik, J. (2006). Computational exercises in machining technology - collection of solved examples, FST TnUAD, ISBN 978-80-8075-193-7, EAN 9788080751 937, Trencin, Slovakia

Steiningerova, J.; Majerik, J. (2010). Surface quality analysis of $102 \mathrm{Cr} 6$ bearing steel after CC6050 insert by hard turning and by SG grinding wheel, Proceedings in manufacturing systems, Vol.5, No.3, (2010) p. 137-142, ISSN 2067-9238

Vasilko, K.; Havrila, M.; Novak-Marcincin, J.; Madl, J.; Zajac, J. (2006). Top trends in machining, technology of machining- part III., Mediast, Zilina, Slovakia 